\title{
Análise dos valores organizacionais na "indústria hoteleira" dos Estados do Rio de Janeiro e São Paulo (Brasil)
}

\section{Analysis of organizational values in the "hotel industry" in the states of Rio de Janeiro and São Paulo (Brazil)}

\author{
Thaís Ribeiro Niedzwiecki (NIEDZWIECKI, T. R.)*, \\ Andréia de Lima (LIMA, A.) ${ }^{* *} \mathrm{e}$ \\ Rogério João Lunkes (LUNKES, R. J.) ${ }^{* * * *}$
}

\begin{abstract}
RESUMO - Os valores organizacionais são parte fundamental da cultura corporativa de uma empresa. Eles representam os princípios compartilhados, as convicções dominantes, aquilo em que as pessoas de uma organização acreditam. Diante da representatividade do tema para as organizações e da escassez de estudos sobre valores organizacionais no setor hoteleiro, neste estudo se analisou os valores organizacionais em hotéis dos estados do Rio de Janeiro e São Paulo (Brasil). Para atingir tal objetivo, realizou-se uma pesquisa descritiva, com abordagem quantitativa e análise de conteúdo. A relação dos hotéis investigados foi retirada do website da ABIH (Associação Brasileira da Indústria de Hotéis) dos estados do Rio de Janeiro e São Paulo - região Sudeste do Brasil - totalizando 381 empresas hoteleiras. A maioria delas possuía endereço eletrônico disponível, porém a amostra foi composta por 31 hotéis que divulgaram nele seus valores. A partir de então foram analisados quais os elementos estavam presentes nos valores organizacionais desses hotéis. Os resultados mostraram que quando analisados em categorias, os valores relativos à harmonia foram os mais adotados pelos hotéis, seguidos de valores inerentes ao comprometimento e autonomia. Os elementos de destaque foram "ética" e "sustentabilidade", bem como, "lealdade", "excelência", "atitude positiva", "companheirismo", "comprometimento", "responsabilidade social", "cordialidade", "crescimento" e "motivação" apresentando a maior frequência dentre os valores organizacionais divulgados pelos hotéis.
\end{abstract}

Palavras-chave: Turismo; Valores organizacionais; Hotéis; Cultura corporativa.

\footnotetext{
* Formação: Graduação em Ciências Contábeis (Bacharelado) pela Universidade Federal de Santa Catarina (UFSC). Atividade profissional: Contadora. Endereço físico para correspondência: Rua Nossa Senhora do Rosário, 292, Bairro Nossa Senhora do Rosário. CEP: 88110-642 - São José - Santa Catarina (Brasil). E-mail: thais.niedzwiecki@gmail.com

*** Formação: Graduação em Ciências Contábeis (Bacharelado) e Especialização em Gestão Financeira e Controladoria pela Universidade do Oeste de Santa Catarina (UNOESC), Mestranda em Contabilidade pela Universidade Federal de Santa Catarina (UFSC). Atividade profissional: Contadora. Endereço físico para correspondência: Rua Frederico Bortolaz, 957, Panazzolo. CEP: 89560-000 - Videira - Santa Catarina (Brasil). E-mail: lima.a@outlook.com.br

*** Formação: Graduação em Ciências Contábeis (Bacharelado), Mestrado e Doutorado em Engenharia de Produção pela Universidade Federal de Santa Catarina (UFSC). Estágio de Pós-Doutorado pela Universidade de Valência (Espanha). Atividade profissional: Professor do Departamento de Ciências Contábeis e do Programa de Pós-Graduação em Contabilidade e Administração (UFSC). Endereço físico para correspondência: Universidade Federal de Santa Catarina, Centro Sócio-Econômico, Departamento de Ciências Contábeis, Campus Universitário Reitor João David Ferreira Lima, Trindade. CEP: 88040970 - Florianópolis - Santa Catarina (Brasil). Caixa-postal: 476. E-mail: rogeriolunkes@ hotmail.com
} 
ABSTRACT - Organizational values are a fundamental part of the corporate culture of a company. They represent the shared principles, the dominant beliefs, the things that people from an organization believe. Given the representativeness of the theme for the organizations and the lack of studies on organizational values in the hospitality industry, this study analyzed the organizational values in hotel sectors in the states of Rio de Janeiro and São Paulo (Brazil). In order to achieve this goal, it was developed a descriptive research, with quantitative approach and content analysis. The list of hotels that were investigated is from the website ABIH (Brazilian Hotel Industry Association) from Rio de Janeiro and São Paulo - Southeastern Region of Brazil - being 381 hotels. Most of them had internet address available, but the sample was constituted with 31 hotels that revealed in website their values. Then it was analyzed which elements were present in the organizational values of these hotels. The results showed that when analyzed in categories, the values related to harmony were the most adopted by these hotels, followed by values inherent to commitment and autonomy. The prominent elements were "ethical" and "sustainability", as well as "loyalty", "excellence", "positive attitude", "companionship", "commitment", "social responsibility", "warmth", "growth" and "motivation" presenting the highest frequency among organizational values disclosed by these hotels.

Key words: Tourism; Organizational values; Hotels; Corporative culture. 


\section{INTRODUÇÃO}

O Brasil tem registrado um aumento no número de turistas e na geração de receita turística, principalmente por sediar eventos mundiais importantes para o País, como a Copa do Mundo de Futebol da Fédération Internationale de Football Association - FIFA e os Jogos Olímpicos Mundiais (MINISTÉRIO DO TURISMO, 2014). Este ambiente favorece o desenvolvimento no setor hoteleiro do Brasil.

Diante da demanda crescente surge a necessidade de ampliação e construção de novos hotéis e a melhoria na qualidade dos serviços, aumentando a competitividade entre as empresas do setor. Neste cenário, a presença de uma cultura corporativa sólida e valores organizacionais definidos pode agregar valor para um hotel, refletindo na escolha do cliente.

Os valores organizacionais expressam as características principais de uma empresa (MAZZUCCO; ROCHA, 2001), eles definem o que é importante para uma empresa no processo de atingir o sucesso (FREITAS, 1991). Ou seja, uma organização pretende cumprir sua missão e atingir seus objetivos, respeitando alguns princípios e características estabelecidas nos seus valores.

A disseminação dos valores de uma empresa para todos os níveis organizacionais pode trazer benefícios para esta entidade. Lunkes e Schnorrenberger (2009) apontam que identificar e definir a razão de ser de uma organização, suas pretensões em termos de evolução e seu conjunto de crença e valores que pautarão suas ações são importantes para a antecipação de eventos futuros. Nos quais, maximiza-se o uso das potencialidades existentes, se inibe e corrige os efeitos dos pontos fracos e desenvolve capacidades e competências cruciais para a continuidade da organização.

O reconhecimento dos valores, por parte da organização, gera fatores positivos como satisfação no trabalho e o comprometimento profissional (GOMES; VIEIRA, 2013). Uma vez que empregados de forma significativa, os valores organizacionais também diminuem desigualdades e consequentes ameaças à produção de resultados econômicos (KABANOFF; WALDERSEE; COHEN, 1995). As diferentes maneiras em que as instituições tentam encontrar um equilíbrio sustentável moldam valores entre concorrentes, criando estruturas globais de valores.

Os valores organizacionais formam a base central filosófica de cada organização. Eles são responsáveis em direcionar todo conjunto de ações e decisões dos 
gestores e empregados. Sem eles uma instituição perde seu guia condutor, isto pode gerar graves problemas éticos e comportamentais, levando a organização a perder sua legitimidade perante a sociedade (LUNKES; SCHNORRENBERGER, 2009).

A importância que valores geram para uma organização, despertou o interesse de pesquisadores sobre o tema. A literatura sobre valores engloba diversos segmentos: Anunciação e Zoboli (2008) investigaram os valores de hospitais; Van Beverhoudt et al. (2010) e Gomes e Vieira (2013) analisaram os valores de instituições de ensino; Carvalho, Oliveira e Silva (2013) deram atenção para as intuições públicas; e, Kabanoff, Waldersee e Cohen (1995), Tamayo, Mendes e Paz (2000) e Pacheco, Lunkes e Lima (2015) investigaram empresas no geral. Contudo, pouca atenção foi dada na literatura para o setor hoteleiro.

Diante do apresentado, estabeleceu-se como problema de pesquisa: quais seriam os valores organizacionais de empresas hoteleiras dos estados do Rio de Janeiro e São Paulo (Brasil)? Para satisfazer a questão de pesquisa, estabeleceu-se como objetivo geral analisar os valores institucionais em hotéis do Rio de Janeiro e São Paulo (Brasil).

Considera-se que a pesquisa é relevante, pois se buscou identificar valores que serviam como código de conduta, que definiam as características fundamentais dos hotéis no Brasil e, representavam a maneira de pensar e agir. As quais poderiam conferir ou não uma vantagem competitiva por meio de incremento da qualidade de serviços, melhoria do ambiente de negócios e consequentemente, melhoria do desempenho. Estudos desta natureza são importantes, pois revelam a status da institucionalização dos valores, fundamentais ao sucesso dos negócios. Também pode fornecer insights sobre o desenvolvimento dos valores institucionais nas organizações brasileiras, bem como o tipo e número de elementos adotados.

O presente artigo está estruturado em cinco tópicos, sendo essa "Introdução" o primeiro. No tópico 2, "Valores Organizacionais", abordam-se os aspectos essenciais para entendimento do conceito e objetivos, além de estudos simulares sobre o tema. No tópico 3, "Procedimentos Metodológicos", se expõem os procedimentos metodológicos adotados para a aplicação do estudo. $\mathrm{Na}$ sequência, no tópico 4 se trata da “Apresentação dos Resultados". E por fim, no tópico 5 são expostas as "Considerações Finais" deste artigo. 


\section{VALORES ORGANIZACIONAIS}

Valores é o conjunto de princípios e crenças que se considera importante e que são evidenciados através das características de um indivíduo ou grupo (GOMES; VIEIRA, 2013). Esses princípios e metas orientam o comportamento do indivíduo (TAMAYO; MENDES; PAZ, 2000) influenciando sua forma de pensar e agir (GOMES; VIEIRA, 2013).

A existência dos valores não está condicionada ao indivíduo (pessoa), podendo ser aplicada também às empresas. No contexto organizacional, os valores são elementos centrais da cultura corporativa (HATCH, 1993), contribuindo, assim, para determinar a identidade de uma organização. Eles representam a essência da filosofia de uma empresa e orientam o comportamento esperado de seus colaboradores no dia-a-dia (LEITE; RENAULT, 2014).

Porém, apesar das semelhanças Leite e Renault (2014) alertam que não se deve confundir valor individual com o valor organizacional. Os valores pessoais são considerados indicadores das motivações do indivíduo, já os organizacionais tratam das percepções compartilhadas pelos colaboradores, que orientam o funcionamento e a vida de uma organização (TAMAYO, 1998).

Portanto, é importante que os valores de uma organização sejam disseminados e adotados por todos os colaboradores. A adoção dos valores organizacionais por todos os colaboradores de uma empresa facilita o trabalho em equipe e melhora o foco para atingir os objetivos da organização, sendo que os valores influenciam e orientam as ações dos funcionários.

Tamayo e Gondim (1996) definem valores como princípios ou crenças, organizados hierarquicamente, relativos a estados de existência ou a modelos de comportamento desejáveis que orientam a vida da empresa e estão ao serviço de interesses individuais, coletivos ou mistos. Os autores destacam quatro aspectos desta definição:

- O aspecto cognitivo: a organização possui crenças relacionadas a diversas dimensões da vida organizacional - produção, qualidade, interações pessoais, respeito às normas etc. Quando essas crenças são enfatizadas e socialmente aceitas como 
princípios que orientam a vida da organização, são consideradas valores, e funcionam com padrões para o julgamento e a justificação do comportamento de si e de outros.

- O aspecto motivacional: a raiz dos valores organizacionais é motivacional, eles expressam interesses e desejos de alguém. Esse alguém pode ser um indivíduo ou um conjunto de membros da empresa. Assim, os valores organizacionais representam metas mais ou menos conscientes da empresa.

- A função dos valores: os valores têm como função orientar a vida da empresa, guiar o comportamento dos seus membros. Eles são determinantes da rotina diária na organização, já que orientam a vida da pessoa e determinam a sua forma de pensar, de agir e de sentir. Não somente o comportamento do indivíduo é influenciado pelos valores, mas também o julgamento que ele faz do comportamento dos outros, pertinente ao sistema organizacional. Os valores podem ser considerados como um projeto para a organização e um esforço para atingir as metas por ela fixadas.

- Hierárquico: as pessoas, as organizações e as culturas se diferenciam entre si, não tanto pelo fato de possuir valores diferentes, mas pela organização hierárquica dos mesmos. Os valores organizacionais implicam necessariamente uma preferência, uma distinção entre o importante e o secundário, entre o que tem valor e o que não tem.

O elemento hierárquico dos valores organizacionais pressupõe que os membros da organização não agem como meros observadores, mas como atores que participam, que tomam partido, que transformam o ambiente organizacional e tentam se impor e se fazer reconhecer no meio social (TAMAYO; MENDES; PAZ, 2000).

\subsection{A IMPORTANCIA DOS VALORES NO CONTEXTO ORGANIZACIONAL}

Os valores organizacionais são elementos importantes para estabelecer a identidade social de uma empresa, tornando-a distinta em relação às demais organizações (TAMAYO; GONDIM, 1996; GOMES; VIEIRA, 2013; LEITE; RENAULT, 2014).

Moraes (2016) enfatiza que eles são responsáveis por manter o foco na conduta e na ética empresarial, bem como pela maneira de agir da empresa e de seus colaboradores. Logo, os valores desempenham funções normativas e morais, ao 
sinalizarem o que é certo ou errado e o que deve ou não ser feito (FERREIRA; FERNANDES; SILVA, 2009).

Os valores de uma empresa contribuem também na coordenação dos colaboradores em direção ao alcance dos objetivos da organização, pois têm a função de vincular as pessoas, de modo que elas permaneçam dentro do sistema e executem as funções que lhes foram atribuídas (LEITE; RENAULT, 2014). Criam entre os empregados um modelo mental homogêneo, relativo ao funcionamento e à missão da organização (LEITE; RENAULT, 2014) evitando percepções diferentes que, certamente, teriam repercussões no comportamento e atitudes dos empregados, pois os valores são assimilados em suas estruturas cognitivas (GOMES; VIEIRA, 2013).

\subsection{DIMENSÕES DOS VALORES ORGANIZACIONAIS}

Um dos principais autores brasileiros na área de valores organizacionais, Álvaro Tamayo (FERREIRA; FERNANDES; SILVA, 2009), coordenou uma linha de pesquisa que buscou fundamento na teoria de valores culturais de Schwartz (1999; SCHWARTZ; ROS, 1995), estendendo-a ao âmbito das organizações e validando um Inventário de Valores Organizacionais (IVO).

De acordo com esta linha de pesquisa, toda organização pode ser vista como um grupo cultural específico que, para sobreviver, necessita atender a três necessidades fundamentais: (i) a compatibilização dos interesses individuais e coletivos; (ii) o estabelecimento de uma estrutura que garanta o alcance de seus objetivos; e, (iii) o estabelecimento de relações com o ambiente físico e social no qual está inserida (TAMAYO; MENDES; PAZ, 2000). Para tanto, recorre a determinados valores que irão orientar seu cotidiano, em razão de serem percebidos como a forma apropriada de responder e satisfazer a essas três necessidades.

Tais valores, segundo Tamayo, Mendes e Paz (2000), estruturam-se em torno de seis polos axiológicos distribuídos em três dimensões bipolares - autonomia versus conservadorismo, hierarquia versus igualitarismo e harmonia versus domínio -, as quais se encontram associadas, respectivamente, à satisfação dos três tipos de necessidades apontadas. Estas três dimensões constituíram a base teórica para a construção e validação do Inventário de Valores Organizacionais. 
Tamayo, Mendes e Paz (2000) explicam que o polo autonomia avalia a tendência da organização em acreditar que o empregado é uma entidade autônoma, habilitada para perseguir os seus próprios interesses e fixar as suas metas em harmonia com as metas e normas da organização. Já o polo conservadorismo avalia o quanto a organização valoriza a necessidade de conservação de usos, costumes e estruturas de poder já existentes promovendo a manutenção do status quo e da interdição de comportamentos que possam perturbar as normas e as tradições da empresa.

O polo hierarquia representa a valorização por parte da organização da autoridade, do poder social, da influência, da fiscalização e da supervisão. E, o polo igualitarismo avalia a preocupação da empresa com o bem-estar dos outros, da organização em geral, a existência de poucos níveis de autoridade e a opção por um gerenciamento de tipo participativo.

O polo domínio reflete a vontade de afirmação assertiva da empresa através do domínio dos recursos materiais, do mercado, da tecnologia e do conhecimento na área específica de atuação. E, por fim, o polo harmonia avalia o acomodamento harmônico da empresa com o seu meio ambiente, respeitando a natureza e as empresas concorrentes.

\subsection{ESTUDOS SIMILARES SOBRE VALORES INSTITUCIONAIS}

Diferentes estudos empíricos sobre valores institucionais foram realizados em âmbito nacional e internacional, na sequência descrevem-se os principais resultados encontrados.

Kabanoff, Waldersee e Cohen (1995) pesquisaram revistas internas, em pronunciamentos sobre a missão e nos relatórios anuais de 88 empresas australianas, referências a valores (autoridade, comprometimento, liderança, produtividade, eficiência etc.). E classificaram as empresas em grupos axiológicos diferentes de acordo com as diferenças na frequência relativa com que as empresas faziam referência a esses valores.

Tamayo, Mendes e Paz (2000) utilizaram uma abordagem diferente de Kabanoff, Waldersee e Cohen (1995) e estudaram os valores organizacionais a partir da percepção que os empregados têm dos valores existentes e praticados na sua empresa. 
Os autores buscaram indícios sobre a forma como os objetivos de cinco organizações brasileiras estavam sendo captados pelos seus membros. $\mathrm{O}$ resultado foi um Inventário de Valores Organizacionais (IVO) constituído de 36 valores distribuídos em seis polos hierarquia, igualitarismo, autonomia, conservadorismo, domínio e harmonia.

Anunciação e Zoboli (2008) confrontaram a literatura existente sobre os valores esperados para hospitais, com os valores declarados pelos hospitais em suas páginas na internet. Os resultados mostraram que os hospitais reconhecem nos valores declarados em suas páginas, a expectativa social em relação a uma instituição que, embora possa ter estrutura burocrática e organizacional com muitas semelhanças para com as empresas, diferencia-se destas por lidar com a saúde e vida das pessoas, que são, ao mesmo tempo, bens e direitos. Expressam o zelo que o hospital tem de dedicar a estes bens e direitos, por intermédio dos administradores e demais profissionais da instituição para que, assim, a organização hospitalar imprima sua marca e compromisso social e transmita confiança aos pacientes.

Van Beverhoudt et al. (2010) realizaram estudo sobre o alinhamento entre valores pessoais e institucionais que afetavam a construção e manutenção de culturas organizacionais saudáveis. O objetivo do estudo foi confrontar valores organizacionais da Universidade de Zulia, na Venezuela e os valores praticados pelos diretores educacionais. Os resultados mostraram que os valores mais praticados pelos diretores educacionais foram lealdade, sucesso, saúde, felicidade, a excelência, a solidariedade, trabalho e paz. Os valores organizacionais da instituição de ensino estavam relacionados com os praticados pelos diretores de ensino.

Gomes e Vieira (2013) relataram os valores organizacionais de uma instituição pública de ensino, com base na percepção dos servidores da instituição pesquisada. Os autores utilizaram o IVO de Tamayo, Mendes e Paz (2000) e, os resultados mostraram que nenhum dos valores pesquisados demonstrou muita importância ou extrema importância para a instituição, conforme a percepção dos servidores. Porém, os valores considerados pelos autores como relacionados à hierarquia - preservação dos costumes vigentes da organização; tradição de respeito às ordens; respeito às pessoas com cargo de chefia; respeitar as regras e normas estabelecidas pela organização; controle do serviço executado; respeito aos níveis de autoridade; preocupação com o cumprimento de horários e compromissos; acompanhamento e avaliação contínua das tarefas; 
utilização de recursos sem causar danos ao meio ambiente; e, proteção ao meio ambiente - apresentaram um grau de relevância maior que os demais.

Carvalho, Oliveira e Silva (2013) também utilizaram a mesma metodologia de Tamayo, Mendes e Paz (2000). Contudo, buscaram identificar os valores organizacionais de quatro instituições públicas através da percepção dos servidores. Os resultados mostraram que dentro da mesma organização houve divergências sobre os valores que são priorizados. Os gestores enfatizavam valores relacionados a autonomia, enquanto os empregados destacavam que valores relativos a hierarquia possuíam maior destaque.

Com foco no setor de serviços Leite e Renault (2014) analisaram os valores organizacionais de acordo com a percepção dos funcionários de empresas, utilizando também o IVO de Tamayo, Mendes e Paz (2000). Os resultados mostraram que, conforme a percepção dos colaboradores, as empresas investigadas tinham uma gestão conservadora e hierárquica, com foco em valores relacionados a controles e processos internos, o que, de acordo com os autores, traz aspectos negativos a essas organizações.

Pacheco, Lunkes e Lima (2015) analisaram os valores organizacionais divulgados por grandes empresas brasileiras, mostrando frequente utilização de palavras como sustentabilidade, integridade, respeito, ética e excelência, as quais foram elencadas com maior índice de utilização nos valores institucionais.

Conforme se pode observar pouca atenção tem sido dada na literatura a estudos sobre o desenvolvimento de valores organizacionais em empresas hoteleiras, ressaltando a importância da presente pesquisa.

\section{PROCEDIMENTOS METODOLÓGICOS}

Tradicionalmente, duas abordagens têm sido utilizadas para identificar e avaliar os valores organizacionais. De acordo com Tamayo, Mendes e Paz (2000), a primeira, estuda os valores a partir de documentos oficiais da empresa (relatórios anuais, estatutos, discursos etc.). E a segunda consiste em utilizar a média dos valores individuais dos membros da organização como estimativa dos valores organizacionais. Tendo em vista que frequentemente existe incongruência entre os valores pessoais dos 
empregados e os valores organizacionais, podendo levar o resultado obtido pela segunda abordagem a não expressar de forma adequada os valores da organização (TAMAYO; MENDES; PAZ, 2000), optou-se por adotar uma metodologia próxima da primeira abordagem.

\subsection{ENQUADRAMENTO METODOLÓGICO}

Quanto aos objetivos, considera-se esta pesquisa descritiva, uma vez que se propôs a analisar valores organizacionais em hotéis dos Estados do Rio de Janeiro e São Paulo (Brasil). De acordo com Triviños (1987) um estudo descritivo busca descrever com exatidão os fatos e fenômenos de determinada realidade.

No que tange aos procedimentos, a técnica empregada neste estudo é a análise de conteúdo, tendo em vista que se empregam métodos sistemáticos, admitindo inferir informações e conhecimentos referentes aos valores organizacionais.

Em relação à abordagem do problema a pesquisa é caracterizada como predominantemente quantitativa. Richardson (1999) destaca que uma das características da pesquisa quantitativa é a utilização de técnicas estatísticas para o tratamento das informações.

\subsection{SELEÇÃO DA AMOSTRA ANALISADA}

Os Estados de Rio de Janeiro e São Paulo foram escolhidos para fazer parte do estudo por serem destaque na atividade turística no Brasil. De acordo com o Portal Brasil (2013) os dois estados eram líderes no turismo brasileiro e suas capitais eram os destinos mais competitivos no setor hoteleiro (PORTAL BRASIL, 2015).

Para seleção dos hotéis que fizeram parte deste estudo, foram considerados todos os hotéis dos Estados do Rio de Janeiro e São Paulo, associados à ABIH (Associação Brasileira da Indústria de Hotéis) até novembro de 2014.

A coleta dos valores organizacionais foi feita por meio dos websites das próprias empresas hoteleiras. Primeiro foram selecionadas 381 empresas associadas à ABIH. Destas, 100 não possuíam ou tinham indisponíveis seus websites. Em seguida, foram acessados os websites dos 281 hotéis restantes e, verificado que 250 hotéis não 
apresentavam descrição dos valores organizacionais em seus websites. Resultando em um total de 31 hotéis que divulgaram seus valores organizacionais em seus websites, e fizeram parte da amostra final deste estudo.

\subsection{PROCEDIMENTOS PARA COLETA E ANÁLISE DE DADOS}

Para atingir o objetivo do presente estudo, foram coletados os valores organizacionais divulgados por cada hotel que compôs a amostra, em novembro de 2014. Os resultados foram tabelados no software Excel® e confrontados, tornando possível identificar a quantidade total de elementos do valor organizacional divulgados e a frequência que cada um apresentava.

Em seguida, elementos dos valores organizacionais identificados foram categorizados de acordo com os polos axiológicos propostos por Tamayo et al. (2000), buscando identificar qual agrupamento de valores apresentava maior destaque.

Nem todas as empresas hoteleiras disponibilizavam os valores organizacionais em seus websites, sendo uma limitação deste estudo. Outra limitação reside no fato de que os valores foram analisados a partir dos elementos que a empresa hoteleira divulgou, sendo que a empresa pode não aplicar efetivamente os valores que constam em seus websites, ou ainda, os valores divulgados pelas empresas podem divergir dos valores percebidos pelos seus colaboradores (TAMAYO; MENDES; PAZ, 2000).

\section{APRESENTAÇÃO DOS RESULTADOS}

Esse tópico de apresentação e análise dos dados divide-se em duas partes. $\mathrm{Na}$ primeira parte apresentam-se os valores identificados nas empresas hoteleiras quanto à ocorrência de cada um deles e na segunda parte realizam-se as discussões e reflexões.

\subsection{VALORES IDENTIFICADOS NAS EMPRESAS HOTELEIRAS}

O estudo realizado mostrou a quantidade de hotéis, associados à $\mathrm{ABIH}$, que apresentavam seus valores organizacionais em seus websites, conforme Tabela 1: 
TABELA 1 - RELAÇÃO DE HOTÉIS ASSOCIADOS À ABIH POR ESTADO

\begin{tabular}{lccc} 
& $\begin{array}{c}\text { RIO DE } \\
\text { JANEIRO }\end{array}$ & SÃO PAULO & TOTAL \\
Associados à ABIH & 198 & 183 & 381 \\
\hline Sem website no cadastro da ABIH & $(89)$ & $(11)$ & $(100)$ \\
\hline Subtotal & 109 & 172 & 281 \\
\hline Não apresentavam valores & $(90)$ & $(160)$ & $(250)$ \\
\hline Total & 19 & 12 & 31 \\
\hline
\end{tabular}

FONTE: Dados da pesquisa, 2014.

Apesar de o Rio de Janeiro destacar-se em número de hotéis associados, predominou no Estado a quantidade de hotéis que não apresentavam endereço eletrônico. Em uma economia na qual cada vez mais os recursos tecnológicos ganham destaque, o fato de $45 \%$ dos hotéis do Estado do Rio de Janeiro não possuírem o website disponível chamou a atenção. Principalmente, pelos benefícios que um website pode trazer para uma empresa do ramo hoteleiro. Fon e Francisco (2016) destacam que "principalmente no ramo hoteleiro, a primeira visita do cliente é feita na maioria das vezes através da internet, seja no site do hotel ou em buscadores online". O Estado do Rio de Janeiro teve o maior número de hotéis que divulgaram valores organizacionais em seus websites: 19 hotéis.

Os hotéis do Estado de São Paulo, tinham, em sua maioria, os websites disponíveis. Contudo, a quantidade de hotéis que divulgaram os valores organizacionais - 12 hotéis - foi inferior ao Estado do Rio de Janeiro.

Os dados também mostraram a quantidade de valores organizacionais adotados por cada hotel analisado (QUADRO 1). Tem-se que a maioria dos hotéis agregou conjunto de condutas para o bom desempenho dos serviços prestados e da convivência pessoal.

QUADRO 1 - QUANTIDADE DE VALORES ADOTADOS POR CADA HOTEL DA AMOSTRA.

\begin{tabular}{|l|l|c|}
\hline HOTEL & \multicolumn{1}{|c|}{ ESTADO } & $\begin{array}{c}\text { QUANTIDADE DE VALORES } \\
\text { AGREGADOS }\end{array}$ \\
\hline HOTEL A & São Paulo & 12 \\
\hline HOTEL B & Rio de Janeiro & 10 \\
\hline HOTEL C & Rio de Janeiro & 10 \\
\hline HOTEL D & Rio de Janeiro & 10 \\
\hline HOTEL E & Rio de Janeiro & 10 \\
\hline HOTEL F & Rio de Janeiro & 10 \\
\hline HOTEL G & Rio de Janeiro & 10 \\
\hline HOTEL H & Rio de Janeiro & 10 \\
\hline HOTEL I & Rio de Janeiro & 10 \\
\hline HOTEL J & Rio de Janeiro & Continua... \\
\hline
\end{tabular}


Continuação.

\begin{tabular}{|l|l|c|}
\hline HOTEL K & Rio de Janeiro & 9 \\
\hline HOTEL L & São Paulo & 9 \\
\hline HOTEL M & Rio de Janeiro & 8 \\
\hline HOTEL N & São Paulo & 8 \\
\hline HOTEL O & Rio de Janeiro & 6 \\
\hline HOTEL P & São Paulo & 6 \\
\hline HOTEL Q & São Paulo & 6 \\
\hline HOTEL R & São Paulo & 6 \\
\hline HOTEL S & Rio de Janeiro & 5 \\
\hline HOTEL T & São Paulo & 5 \\
\hline HOTEL U & São Paulo & 5 \\
\hline HOTEL V & Rio de Janeiro & 4 \\
\hline HOTEL W & Rio de Janeiro & 4 \\
\hline HOTEL X & Rio de Janeiro & 4 \\
\hline HOTEL Y & São Paulo & 4 \\
\hline HOTEL Z & São Paulo & 4 \\
\hline HOTEL AA & Rio de Janeiro & 3 \\
\hline HOTEL AB & São Paulo & 3 \\
\hline HOTEL AC & Rio de Janeiro & 2 \\
\hline HOTEL AD & São Paulo & 2 \\
\hline HOTEL AE & Rio de Janeiro & 1 \\
\hline & &
\end{tabular}

FONTE: Dados da pesquisa, 2014.

Observou-se que a quantidade média de valores organizacionais divulgada em cada hotel foi 6,6. Essa média foi superior nos hotéis do Estado do Rio de Janeiro $(7,2)$ se comparada aos do Estado de São Paulo (5,8). Contudo, a quantidade de hotéis analisados no Estado de São Paulo - 12 hotéis - também foi inferior à quantidade de hotéis do Estado do Rio de Janeiro - 19 hotéis. Não permitindo realizar uma inferência mais certa sobre esses números.

Com base no Quadro 1, concluiu-se que o hotel que mais possuía valores organizacionais foi o Hotel A, adotando 12 práticas diferentes de conduta. Em seguida, com uma quantidade de 10 valores organizacionais cada se situaram os Hotéis B, C, D, E, F, G, H, I e J. Estes nove hotéis fazem parte de uma rede, todos aderindo aos mesmos princípios. Em terceiro lugar se posicionou o Hotel H, com 9 valores utilizados. Já os Hotéis $\mathrm{AC}, \mathrm{AD}$ e $\mathrm{AE}$ apresentaram a quantidade mais baixa de valores organizacionais, 2, 2 e 1 respectivamente. Contudo, percebeu-se que a maioria dos hotéis considerou mais do que 4 valores organizacionais, o que pode ser reflexo da preocupação dessas organizações em transmitir sua personalidade e seus princípios não somente para os colaboradores, mas também para os clientes e outros stakeholders. 
O estudo realizado mostrou também que o setor hoteleiro dos dois estados que mais estavam recebendo turistas no Brasil, adotou 48 valores institucionais. Dentre esses, 23 foram evidenciados em mais de um hotel coletado.

A partir da análise do Quadro 2, percebeu-se que as práticas mais utilizadas em relação ao número de hotéis que apresentaram valores foram a ética - presente em 22 hotéis - e a sustentabilidade - com uma frequência igual a 21. Esses números podem ser reflexo da crescente preocupação não somente do setor hoteleiro, mas das organizações em geral, com questões éticas e desenvolvimento sustentável.

Já a excelência e a lealdade apareceram dentre os valores de 14 hotéis investigados. Dentre os valores organizacionais que não foram encontrados com tanta frequência se destacam a simplicidade, valorização e conforto. Cada um deles foi indicado por apenas dois hotéis.

QUADRO 2 - QUANTIDADE DE VALORES INSTITUCIONAIS IDENTIFICADOS NOS HOTÉIS DA AMOSTRA

\begin{tabular}{|l|c|c|}
\hline \multicolumn{1}{|c|}{ VALOR } & OCORRÊNCIA & $\begin{array}{c}\text { EXCLUSÃO DE HOTÉIS DE } \\
\text { MESMA REDE }\end{array}$ \\
\hline Ética & 22 & 11 \\
\hline Sustentabilidade & 21 & 11 \\
\hline Excelência & 14 & 4 \\
\hline Lealdade & 14 & 3 \\
\hline Atitude Positiva & 11 & 2 \\
\hline Companheirismo & 11 & 7 \\
\hline Responsabilidade Social & 10 & 6 \\
\hline Comprometimento & 9 & 1 \\
\hline Cordialidade & 9 & 8 \\
\hline Integridade & 9 & 1 \\
\hline Crescimento & 9 & 1 \\
\hline Solidariedade & 9 & 1 \\
\hline Motivação & 9 & 4 \\
\hline Inovação & 5 & 5 \\
\hline Respeito & 5 & 2 \\
\hline Acessibilidade & 4 & 4 \\
\hline Qualidade & 4 & 3 \\
\hline Responsabilidade & 3 & 3 \\
\hline Segurança & 3 & 3 \\
\hline Transparência & 3 & 2 \\
\hline Simplicidade & 2 & 2 \\
\hline Valorização & 2 & 2 \\
\hline Conforto & 2 & \\
\hline
\end{tabular}

FONTE: Dados da pesquisa, 2014.

Considerando as redes de hotéis como uma só organização - já que os valores organizacionais são os mesmos para todos os hotéis da rede - concluiu-se que a ética e a 
sustentabilidade foram as práticas mais utilizadas com 11 ocorrências. Porém, os valores menos adotados passaram a ser crescimento, solidariedade e motivação, cada um foi presente em apenas 1 hotel.

\subsection{DISCUSSÕES}

Os valores identificados nos hotéis investigados podem ser classificados de acordo com os polos axiológicos identificados por Tamayo et al. (2000), conforme exposto no Quadro 3.

Verificou-se que ao contrário dos demais estudos relacionados ao tema, os valores do polo axiológico da harmonia são os mais presentes na cultura dos hotéis investigados. Tal fator pode ser justificado pela preocupação das organizações com a opinião dos stakeholders, que estão mais atentos para temas como transparência, responsabilidade social e meio ambiente. Em seguida, os valores mais adotados foram os de conservadorismo e autonomia, indo ao encontro aos resultados obtidos por Carvalho, Oliveira e Silva (2013).

QUADRO 3 - AGRUPAMENTO DE VALORES ORGANIZACIONAIS DOS HOTÉIS POR POLOS AXIOLÓGICOS

\begin{tabular}{|c|c|c|c|}
\hline $\begin{array}{l}\text { POLOS } \\
\text { AXIOLÓGICOS }\end{array}$ & $\begin{array}{l}\text { VALORES ORGANIZACIONAIS } \\
\text { IDENTIFICADOS }\end{array}$ & $\begin{array}{l}\text { QUANTIDADE } \\
\text { DE } \\
\text { OCORRÊNCIA }\end{array}$ & $\begin{array}{l}\text { QUANTIDADE } \\
\text { DE } \\
\text { OCORRÊNCIA } \\
\text { (EXCLUSÃO } \\
\text { REDES) }\end{array}$ \\
\hline Autonomia & $\begin{array}{l}\text { Excelência; Atitude Positiva; Motivação; } \\
\text { Inovação. }\end{array}$ & 39 & 13 \\
\hline Conservadorismo & $\begin{array}{lr}\text { Lealdade; Integridade; } & \text { Responsabilidade; } \\
\text { Segurança; } & \text { Simplicidade; } \\
\text { Comprometimento. } & \\
\end{array}$ & 40 & 26 \\
\hline Hierarquia & Crescimento; Qualidade; Valorização. & 15 & 7 \\
\hline Igualitarismo & $\begin{array}{l}\text { Companheirismo; Cordialidade; Respeito; } \\
\text { Acessibilidade; Conforto. }\end{array}$ & 31 & 12 \\
\hline Domínio & Crescimento; Qualidade; Valorização. & 15 & 7 \\
\hline Harmonia & $\begin{array}{l}\text { Ética; Sustentabilidade; Responsabilidade } \\
\text { Social; Solidariedade; Transparência. }\end{array}$ & 65 & 33 \\
\hline
\end{tabular}

FONTE: Dados da pesquisa, 2014.

Os resultados evidenciaram também que, ao menos no que veiculavam em seus meios eletrônicos, os gestores dos hotéis, como prestadores de serviços, demonstraram compreender que o bem-estar das pessoas envolvidas e a responsabilidade com a 
sustentabilidade seria essencial para o bom funcionamento do negócio. Exemplo disso foram declarações como: "cuide dos funcionários, e eles cuidarão dos clientes"; "a nossa dedicação ao cliente aparece em tudo o que fazemos"; "vocação ao bem servir"; "a preocupação com o meio ambiente é um fator muito importante"; e, "a responsabilidade ambiental, pautada na gestão dos recursos naturais e na busca por uma economia sustentável, é prioritária e fator determinante para mitigar o impacto do ser humano no meio ambiente". Nesse sentido, foi encontrada uma diversidade de valores, pois cada indivíduo tem uma maneira diferente de se expressar.

Identificou-se que os administradores precisam cada vez mais considerar atitudes éticas nas suas tomadas de decisões. Porém, é preciso ter critérios para avaliar esse assunto. Uma vez que no âmbito empresarial a ética confunde-se com o gerenciamento, que é uma atividade técnica que utiliza recursos para produzir resultados otimizados. Nessa linha, a ética cobrada é profissional, de cumprir sua obrigação, de realizar bem o trabalho pelo qual foi contratado e alcançar os fins estabelecidos. Porém, com a crescente circulação de informações, o interesse das pessoas aumenta e os empresários passam a fazer uma gestão de duplo caráter, completando a gestão técnica com a gestão ética. Na qual, se prioriza os valores institucionais, embora os lucros possam ser os perenes objetivos do gerenciamento, jamais serão os fins da administração. As empresas mais bem-sucedidas economicamente são aquelas que melhor traçaram os seus rumos. (IASI, 2012).

Os resultados apontaram que a lucratividade não estava sendo a única prioridade do negócio. Os gestores das empresas demonstraram estar conscientes que precisavam buscar a excelência no benefício ao cliente, através de condutas éticas. A maneira como os profissionais forem tratados irá refletir na prestação do serviço ao hóspede, se esta relação não for satisfatória acarretará uma baixa na produtividade.

Essa demanda moral está cada vez mais presente nas organizações, a sociedade está atenta à responsabilidade social das empresas. O estudo feito em hospitais: valores éticos que expressam sua missão de Anunciação e Zoboli (2008) comprova essa prática. Foram encontrados 30 hospitais da Cidade de São Paulo que reconheceram valores declarados em suas páginas, agrupados nas categorias: assistência, administração e compromisso social. Expressaram o zelo que o hospital teria de dedicar a estes bens e direitos, por intermédio dos administradores e demais profissionais da instituição para 
que, assim, a organização hospitalar imprima sua marca e compromisso social e transmita confiança aos pacientes.

\section{CONSIDERAÇÕES FINAIS}

Diante da importância dos valores organizacionais para expressar a identidade de uma empresa e sua contribuição no alcance de seus objetivos, este estudo teve como objetivo principal analisar os valores organizacionais no setor hoteleiro, limitado aos dois estados brasileiros líderes na atividade turística do país: Rio de Janeiro e São Paulo. Para atingir o objetivo proposto, foram identificados que valores organizacionais hotéis do Rio de Janeiro e de São Paulo estavam informando em seus endereços eletrônicos (websites).

A partir dos resultados obtidos na pesquisa, observou-se que dos hotéis do setor hoteleiro dos dois estados, 31 evidenciaram práticas de valores organizacionais e divulgaram quais eram seus valores em meios eletrônicos. Os hotéis que não apresentaram seus valores organizacionais foram 250, o que poderia indicar uma falta de preocupação em relação a essa conduta como diferencial competitivo.

Dentre os 31 hotéis que divulgaram seus valores organizacionais, os resultados demonstraram que em média seis valores foram divulgados por hotel. Demonstrando uma preocupação por parte destas organizações em transmitir os valores presentes em sua cultura.

Dos valores divulgados, destacaram-se a ética e a sustentabilidade como as condutas mais mencionadas, corroborando com os resultados encontrados por Pacheco, Lunkes e Lima (2015) em grandes empresas do Brasil. Se considerados os polos axiológicos dos valores, os que apresentaram maior representatividade foram os de harmonia, comprometimento e autonomia. O que revela uma preocupação dos hotéis com o meio no qual estão inseridos (meio ambiente, sociedade, concorrentes), além de demonstrar cuidado com comportamentos e respeito à normas e incentivar a criatividade e a autonomia dos funcionários.

A aderência dessas preferências de comportamento pode trazer vantagens a essas organizações, por determinar o posicionamento dos hotéis frente aos seus clientes, 
fornecedores, funcionários, comunidade e governo. Esse sistema é fundamental na influência de outras condutas de uma organização, pois condiciona sua interação com aspectos ambientais e define ações e decisões dos colaboradores perante o meio em que estão inseridos.

Destaca-se por fim que uma limitação deste trabalho foi analisar os valores evidenciados pelos hotéis sem poder no momento da pesquisa empreendida confrontar com os valores percebidos pelos seus colaboradores. Pois se a empresa não possuir uma cultura corporativa disseminada, que permita transmitir seus valores a todos os colaboradores ou não praticar efetivamente os valores organizacionais que estabeleceu, os valores que a empresa divulga para o público podem divergir dos valores organizacionais percebidos pelos funcionários e stakeholders.

Como sugestão para trabalhos futuros, menciona-se confrontar os valores divulgados pelas organizações com os valores percebidos pelos colaboradores ou stakeholders. Outra sugestão está na necessidade de expandir a pesquisa ao sistema organizacional (crenças, valores, missão, princípios e propósitos), com intuito de identificar as convicções, as apreciações, as necessidades sociais e as condutas que distinguem um negócio do outro.

\section{REFERÊNCIAS}

ANUNCIAÇÃO, A. L. DA; ZOBOLI, E. Hospital: valores éticos que expressam sua missão. Revista da Associação Médica Brasileira, v. 54, n. 6, p. 522-528, 2008.

CARVAlHO, V. D. DE; OllVEIRA, T. A. DE; SILVA, D. C. DA. Valores organizacionais em instituições públicas brasileiras: percepções dos servidores em diferentes posições hierárquicas e tipos de entidade da administração indireta. RAM. Revista de Administração Mackenzie, v. 14, n. 5, p. 74-103, 2013. Universidade Presbiteriana Mackenzie.

FERREIRA, M. C.; FERNANDES, H. DE A.; SILVA, A. P. C. Valores organizacionais: um balanço da produção nacional do período de 2000 a 2008 nas áreas de Administração e Psicologia. RAM. Revista de Administração Mackenzie, v. 10, n. 3, p. 84-100, 2009.

FRANCISCO, D. J.; FON, C. P. O impacto da internet e novas tecnologias no mercado hoteleiro. RACE - Revista da Administração, v. 1, n. 1, 2016. 
FREITAS, M. E. DE. Cultura organizacional grandes temas em debate. Revista de Administração de Empresas, v. 31, n. 3, p. 73-82, 1991.

GIL, A. C. Métodos e técnicas de pesquisa social. 4. ed. São Paulo: Atlas, 1994.

GOMES, D. C.; VIEIRA, M. DA S. O. C. Valores organizacionais numa instituição pública de ensino do RN. HOLOS, v. 3, p. 77-89, 2013.

HATCH, M. J. The dynamics of organizational culture. Academy of Management Review, v. 18, n. 4, p. 657-693, 1993.

IASI, M. A. Gestão: Técnica e Ética. 2012. Disponível em: <http://www.eticaempresarial.com.br>. Acesso em: 17/12/2014.

KABANOFF, B.; WALDERSEE, R.; COHEN, M. Espoused values and organizational change themes. Academy of Management Journal, v. 38, n. 4, p. 1.075-1.095, 1995.

LEITE, D. A.; RENAULT, L. F. Percepciones de valores organizacionales: contribución a la gestión de personas en el sector servicios. Dimensión Empresarial, v. 12, n. 2, p. 83-94, 2014.

LUNKES, R. J.; SCHNORRENBERGER, D. Controladoria: Na Coordenação dos Sistemas de Gestão. São Paulo: Atlas, 2009.

MAZZUCCO, G. D.; ROCHA, V. DE Q. A importância dos valores nas novas formas organizacionais. Revista de Ciências da Administração, 1. jan. 2001.

MINISTÉRIO DO TURISMO. Disponível em: <http://www.turismo.gov.br/turismo/o_ministerio/publicacoes/cadernos_publicacoes/01 estudos_indutores.html>. Acesso em: 15/11/2014.

MORAES, C. Z. A Força dos Valores Organizacionais, Empresas Orientadas para Pessoas e Cultura: Estudo de Caso na JBS-Brasil. Revista de Ciências Gerenciais, v. 20, n. 31, p. 3-10, 2016.

PACHECO, V.; LUNKES, R. J.; LIMA, A. Análise dos valores institucionais em grandes empresas brasileiras. Revista de Administração e Negócios da Amazônia, v. 7, n. 3, p. 14-26, 2015.

PORTAL BRASIL. Disponível em: <http://www.brasil.gov.br/turismo/2013/09/saopaulo-e-rio-de-janeiro-lideram-turismo-no-brasil>. Acesso em: 06/11/2014.

PORTAL BRASIL. Disponível em: <http://www.turismo.gov.br/\%C3\%BAltimasnot\%C3\%ADcias/5748-s\%C3\%A3o-paulo-\%C3\%A9-o-destino-mais-competitivo-dobrasil.html>. Acesso em: 06/07/2015.

RICHARDSON, R. J. Pesquisa social: métodos e técnicas. 3. ed. São Paulo: Atlas, 1999. 
SCHWARTZ, S. H. A theory of cultural values and some implications for work. Applied Psychology: An International Review, v. 48, n. 123-47, 1999.

SCHWARTZ, S. H.; ROS, M. Values in the west: A theoretical and empirical challenge to the individualism-collectivism cultural dimension. World Psychology, v. 1, p. 91$122,1995$.

TAMAYO, A. Valores Organizacionais: sua relação com satisfação no trabalho, cidadania organizacional e comprometimento afetivo. Revista de Administração, v. 33, n. 3, p. 53-63, 1998.

TAMAYO, A.; GONDIM, M. DAS G. C. Escala de valores organizacionais. Revista de Administração, v. 31, n. 2, p. 62-72, 1996.

TAMAYO, A.; MENDES, A. M.; PAZ, M. D. G. T. DA. Inventário de valores organizacionais. Estudos de Psicologia, v. 5, n. 2, p. 289-315, 2000.

TRIVIÑOS, A. N. S. Introdução à pesquisa em ciências sociais: a pesquisa qualitativa em educação. 1. ed. São Paulo: Atlas, 1987.

VAN BEVERHOUDT, E. Z.; SÁNCHEZ, A. P.; LLAMOZAS, B. M.; LEAL, Y. R. Valores de los docentes que desempeñan cargos directivos en la Universidad del Zulia Núcleo Costa Oriental del Lago. Revista de Ciencias Sociales, v. 16, n. 2, p. 260-268, 2010.

Recebido em: 19-03-2015.

Aprovado em: 18-04-2015. 